\title{
The Importance of Cultural Monuments in Greece: How the Cultural Management Is A Definitive Factor for The Sustainable Development in Region of Epirus?
}

\author{
Efthymios Spyridon Georgiou
}

M. Eng. School Spatial Planning and Development Departure Polytechnic University Aristotle Thessaloniki, Greece

\begin{tabular}{ll} 
ARTICLE INFO & ABSTRACT \\
\cline { 1 - 2 } $\begin{array}{l}\text { Keywords: } \\
\text { Architecture }\end{array}$ Epirus & $\begin{array}{l}\text { This paper is focused on the anthropology of space, in architectural and } \\
\text { cultural monuments of the mountainous village of Konitsa. Epirus is region } \\
\text { that presents a harmonious collaboration between nature and people. The } \\
\text { Interviews }\end{array}$ \\
purpose of the anthropological research approach was focused on the way in \\
which the dynamics of cultural heritage are perceived by local residents. \\
The main research question concerns the perceptions of the social actors of \\
the village of Konitsa regarding the cultural monuments in the region. The \\
methodology of fieldwork had as a key tool the use of interviews, charts, \\
discussions with the locals, walks, tours and visits as well as observation of \\
locations, people and monuments. \\
The inhabitants currently living in the wider area of Konitsa, are directly \\
related to the tangible reality of history, folklore and tradition of monuments, \\
something that can be easily detected through a wide range of aspects of the \\
region's "social life"' (Appadurai \& Kopytoff, 1986). Although the cultural \\
and traditional heritage refer to the past, they have a significant impact on the \\
present era and they also have the ability to determine the future. (Bulter \& \\
Rowlahds, 2012). \\
The cultural management is an advantage of Konitsa and the cooperation with \\
the social associations, for example agriculture partnerships, can reduce the \\
unemployment as well as the immigration and help in the economic \\
development. This research paper is based on the fieldwork and theoretical \\
lessons in the Summer School Konitsa 2016 of Border Crossing Network.
\end{tabular}

\section{Introduction}

This research project was carried out during a Summer University in Konitsa, Ioannina located in Epirus Periphery, Greece. Summer University was organized by the University of Ioannina and the Border- Crossing Network.

The scope of this study is the understanding of important environmental and cultural meanings, the establishment of the existing situation concerning the living natural and cultural sources in the area of study, as well as the writing of inhabitants' opinions for the management of cultural sources, which is the base of planning and inscription of long-term orientation and their viable use.

For the completion of this study, photographs and information were collected from local principles (Municipality, local council), on the spot study was conducted at cultural monuments and folk local events. Also, material was collected from interviews with local people.

\subsection{Geographical site of case study}

The meaning of Culture, natural and cultural heritage is closely related to Periphery of Epirus. Urban cities, traditional residences, coastal residences, mountainous ranges, rivers, lakes,

* Corresponding Author E-Mail Address: efthimios_georgiou@yahoo.gr 
traditional bridges, monasteries, people with different idioms and culture, the unique and different natural and cultural heritage of every area constitute the overall image of Epirus Periphery. Municipality of Konitsa occupies the northwestern part of Peripheral Epirus and covers a surface of $1000 \mathrm{~km} 2$, approximately. It is consisted of four distinct anthropogenic units in particular- the same city of Konitsa.

Konitsa in Hellenic Space

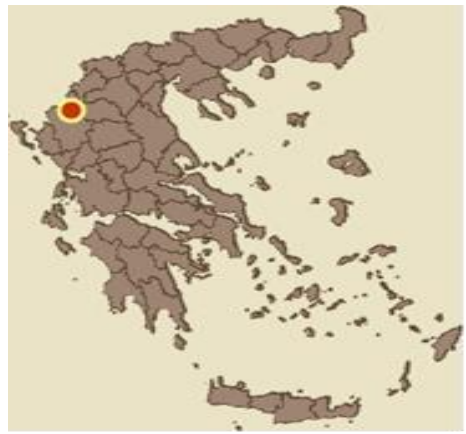

Konitsa in Europe

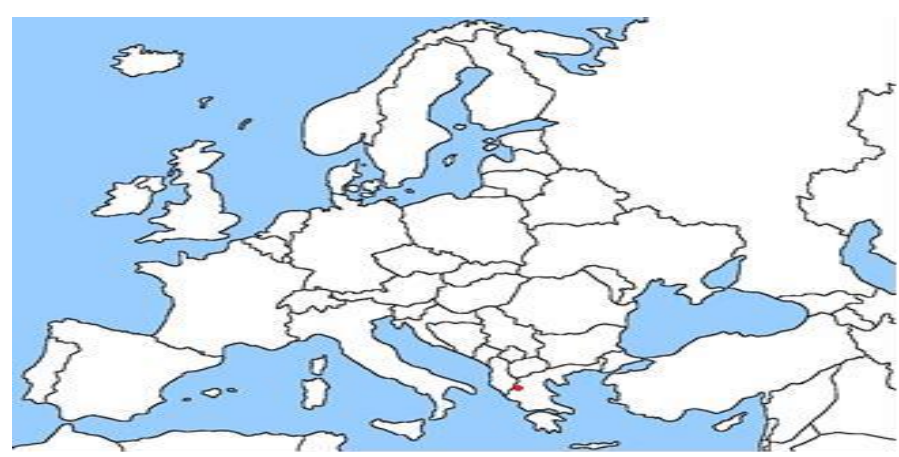

Figure 1. Geographical space of region Konitsa (Source: [web-site, Wikipedia, search: $3 / 10 / 2019,15: 10])$

The variety of its natural and cultural sources in combination with the ultimate memory and consciousness of local people makes it one of the most attractive regions in Greece. Taking into account the importance of these sources for the peripheral economy, the need of their vital utilization is a semantic concern, so as to benefit local people, visitors, peripheral and cultural economy.

\subsection{A view of mosaic in the cultural heritage}

"Culture is the overall of dreams and acts that contribute to the full realization of a person. Culture demands a paradox: to make diversity the principle of unity, to emphasize differences not to arise divisions, but to enrich culture even more."

Deni de Ruzmon

Cultural sources can constitute a basic leverage of financial development and prosperity. It is widely accepted that cultural sources are essential for development effort of areas, mostly those that contain natural and cultural heritage.

The area of Konitsa is famous for its skillful techniques of bridges that remain intact throughout the years and remind us of greatness of mankind.

Undoubtedly, the aimed planning of an area, concerning the completed management of its cultural sources, can lead to its important development. Of course, this can happen through the appropriate utilization of its unique cultural characteristics and the configuration of its cultural identity.

The bridge of Konitsa

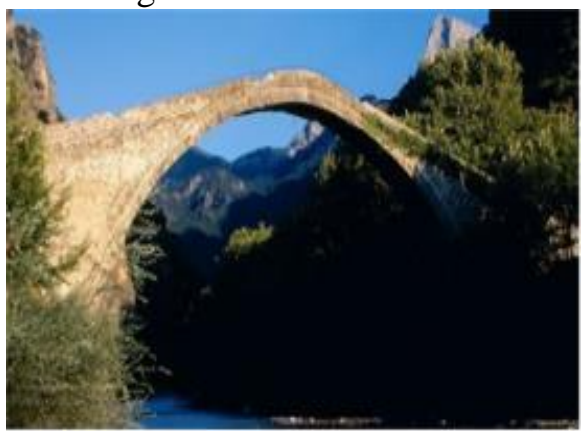

The stone bridge in Epirus (Sarantaporo)

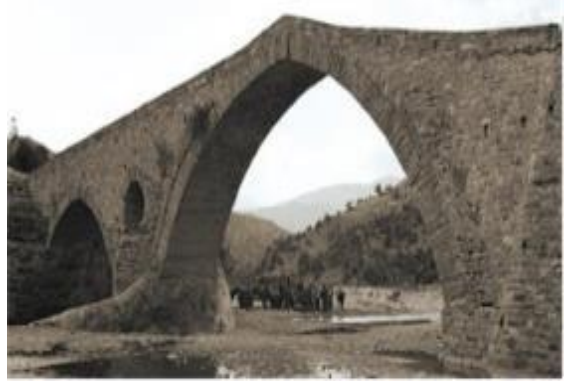

Figure 2: Historical stone's bridges of Konitsa (Source: [web-site,e-konitsa,search:2/10/2019,12:23]) 
Cultural heritage is not only a monument, an object or a place, but it is a general and extended concept that can be transformed and operates in a guiding way for trade, entertainment, economy and politics. Sustainable development follows the same route, it is about a new notion that earns more and more ground in today's society, as it appears in subjects that protect architecture and cultural heritage, the notion of wellness.

\subsection{The relation of suitable development and cultural source}

Wellness or, in other words, sustainable development constitutes a term of modern economic, social and environmental development, having as a principle not to deplete the sustainable sources and the protection of environmental quality, so as to ensure the quality of natural and cultural sources for future generations through their usage and economic blossom. The reconsideration of 2001 established the meaning of wellness or sustainable development in Greece, according to law.

Dragolimni of Smolikas (2200m)

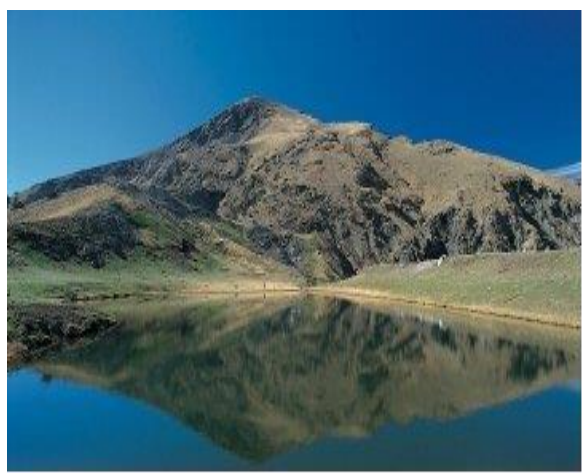

Ravline of Aoos

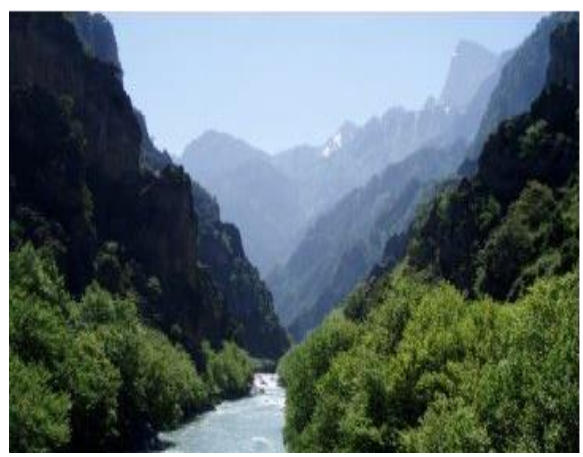

Figure 3.: Natural beauty in mountains of Pindos (Source: [web-site of Municipality, konitsa.gr, search:2/10/2019,6:12])

Now there is a holistic confrontation of things, as far as the environment, society and people are concerned. In this context, Europe Council has specified the relationship between cultural heritage and sustainable development in the following contracts: "European contract for the Landscape" of 2000 and "Framework of the Contract for the Value of Cultural Heritage for the Society" of 2005. Through sustainable development the meaning of cultural heritage is reduced to a new dimension, where it is connected and interdependent directly to social, financial and environmental sector.

\section{Natural habitat in the area of Konitsa}

Rich flora and fauna, astonishing cliffs, of magnitude mountains, lakes, rapids and protected areas synthesize the polymorphic landscape in the area of Konitsa. The area is a habitat of many extinct species.

\section{Methodology of study}

\subsection{Sample}

Research participants $(\mathrm{N}=14) 8$ men and 6 women come from the constituent settlements of Municipality of Konitsa, aged between 20 and 85 years old. Their education level varies from primary school to university level, with the eldest tending to have fewer years of education.

\subsubsection{Method of sampling}

For the choice of the sample, the method of simple random sampling was used (Pharmakis, 1994). For the needs of the quality study-interview, potential participants were approached after their own understanding and consent. Finally, our qualitative study had 14 participants. 


\subsubsection{Meter}

The interview was used in this paper as the main research tool. The semi-structured interview was used because it provides significant freedom to the researcher in order to modify the procedure during its duration.

Many questions included clarifying sub-questions that facilitated the respondents for the answer and helped them to obtain a more sufficient picture of the topic.

\subsection{Validity and reliability}

Keeves (1988) mentions that one of the most basic rules for the conduction of a study is to ensure the precision and reliability of data not only during their selection but also during their processing. So, in this case an effort is made for major objectiveness as far as filtration in the collection and data analysis are concerned.

Validity in every study comes from the fact that if the study would be repeated at any time from any researcher, then the same results should result. According to this logic, planning the questions has become in such a way that they are specific, easy to understand and do not reflect the aim of the study, so as the interviewee is unaffected.

\subsubsection{The process}

Interviews were accomplished during Summer University by the writer of this study, with the scientific guidance of the university lecturers.

The following procedure took place: participants were approached at their work places, recreational areas, square of the settlement. The course of the interview was dependent on each subject, his cooperation attitude and the time of each interview was 25 minutes.

The answers were recorded, edited for the identification of common issues that run the experiences and opinions of the people who took part in the interview. After the end of the interview, the researcher thanked the participants.

\subsubsection{Presentation and analysis of Quality data}

Almost all participants in the interview (N-14) answered that they know the cultural monuments of the area, their value and their meaning. "We live in a blessed area, full of history, tradition and folklore. We love our place and struggle for protection, highlighting and promotion of the historical, cultural and folklore elements."

Answering if and how they realize the coexistence of natural habitat and human, all participants and mostly the elderly stated that: «Our relationship with the natural habitat is a life relation, we are closely connected with the variety of natural environment of our place, which is reflected to our characteristics, habits, everyday life and lifestyle."

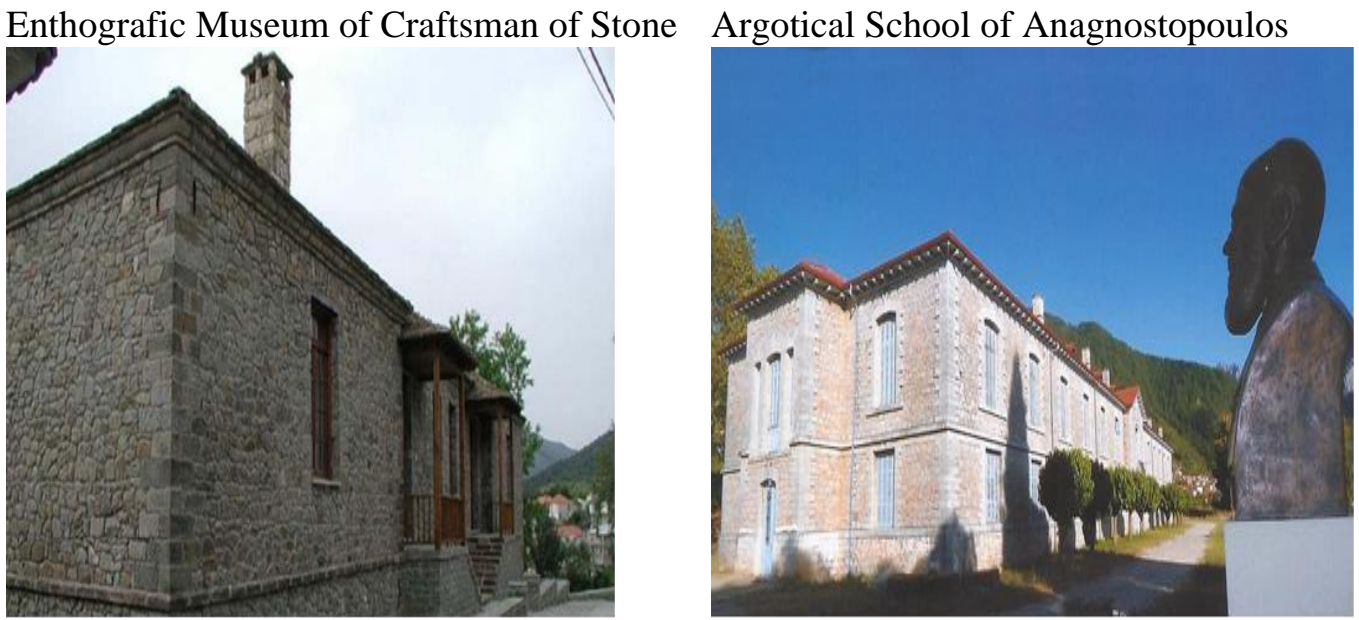

Figure 4. Historical significant museum and school (Source: [web-site, Municipality of Konitsa,search 1/10/2019,14:09]) 
As far as the connection between environment and humans is concerned, the answer came from the eldest people: "Mastoroxoria highlighted us as famous craftsmen of the stone, wood sculptors and local painters. Most men of the villages, known as mpouloukia, have travelled throughout whole Greece and all around the world, from America to Persia."

Interviewees made clear that the elements which make their place special are: "The beautiful, but at the same time, wild mountains, which are crossed by rushing waters of three big rivers and a crowd of tributaries, picturesque traditional settlements, dozens of monuments, stone bridges, historical monasteries and watermills, and most of all, authentic people, who are original with lots of tradition, music and festivals. All these make our place special."

Younger participants, in response to our question about what their place offers, said: "Konitsa is considered as the place of kagiak and offers plenty of activities throughout the whole year, contributing to an alternative way of tourism (rafting, mountain biking, climbing). Also, the utilization of the geopark provides more value to the area, whereas the existence of thermal springs creates unique development opportunities for the area."

\section{Slope of Parachute}

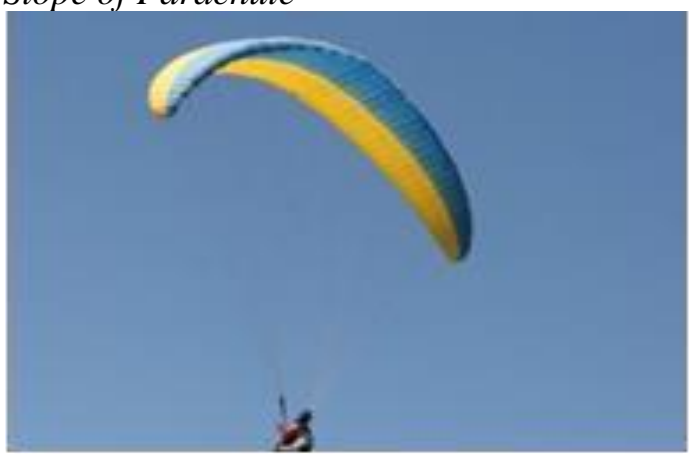

\section{Kayak and Raftig}

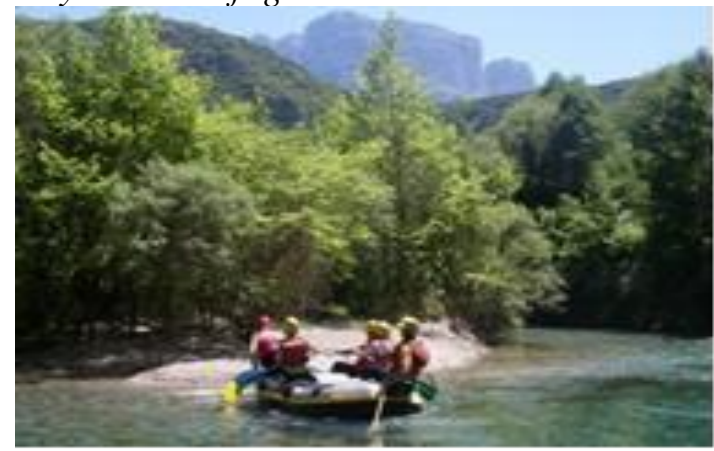

Figure 5. Athletic tourism for suitable management (Source: [webasite of Municipality of Konitsa, search, 4/10/2019,20:44])

Having positive emotions, most of the participants talked about the reduction of time distance from big urban centers because of Egnatia and Ionia road. To questions about weaknesses and worries for the place, everyone pointed out, and mostly the elderly: "In many settlements we stayed a few and aged enough."

Mr. George (85 years old) was disarming: "Everything that is done for tourism is ok, but there should be motives so as the young stay, the winter we are left a few old men with our loneliness for company." The protection, highlighting and promotion of the architectural-cultural monuments were evaluated quite important for the cultural management and development of the area. "There is lack of maintenance to some preserved monuments." (Maria, 28 years old) As far as the weaknesses are concerned, the participants agreed that there is lack of use of rich cultural elements and that there is room for improvement. "The absence of projection concerning cultural events, inadequate marking in places of cultural, historical and religious interest." (Katerina, 40 years old)

Moreover, some of the respondents' opinions focused on supporting local businesses, mainly local agricultural products. "Our place stands out for its gastronomy, several craft units are already operational, and we want support with national and European funding and mainly the connection of gastronomy with tourism, a kind of gastronomic marketing." (Kostas, 38 years old) 


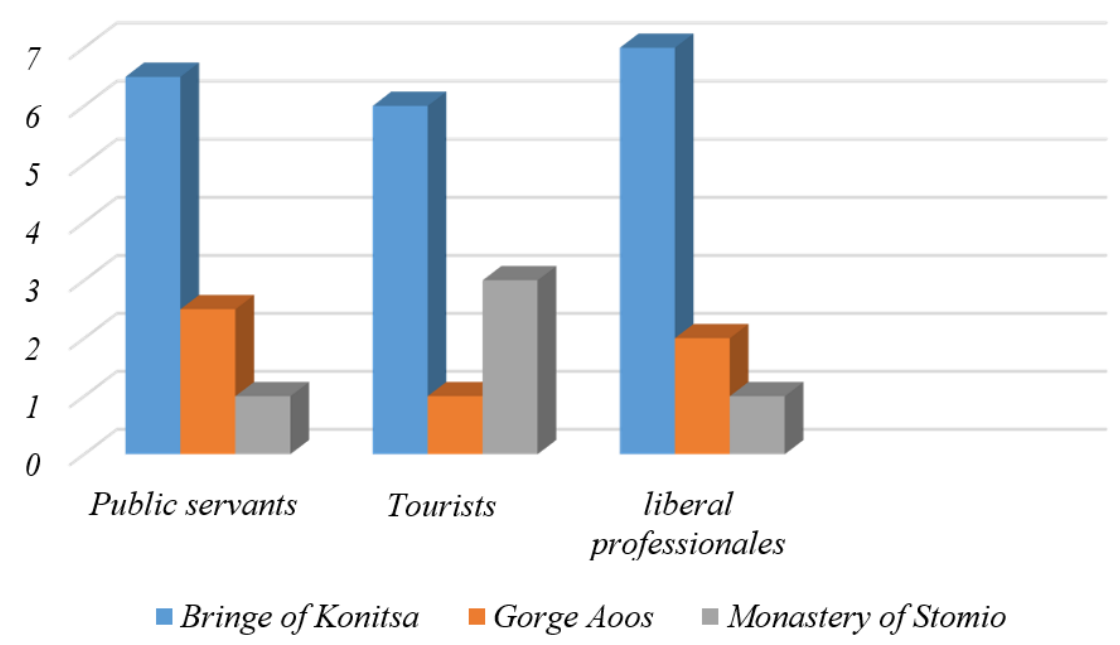

Figure 6. Which is the most important cultural site in region of Konitsa (Source: [self-processing])

Educational programs concerning actions of alternative tourism, supporting new initiatives, but also "the need for exploiting new technologies, so as Konitsa to become more extrovert and competitive." (Despoina, Thomas 23 years old and 25 years old)

All participants, no matter their age and educational level made the point: "Sustainable management of tourism is of great importance for us, the habitants, for businessmen and the whole local community."

Having realized the value of the cultural, economic and tourism development for local community, they ask "there should be public speech, in time confrontation of any possible problems, participation in planning tourism viable activities."

\section{Conclusion}

Historical and cultural sources, local culture, traditional settlements, monumental sets, religious monuments, customs, local activities, gastronomic, musical and folklore wealth combine the unique identity of Epirus Periphery and mostly our study area. This cultural identity is combined with an especially noteworthy natural habitat, which is characterized by unique ecosystems. The recipients of a rational and viable development and management of the cultural and tourist reserves are:

\subsection{Local community}

the exploitation of these sources leads to safeguarding and protection of natural and cultural heredity, for modern and future generations. In addition, it offers to local community the perspective of a fair development of local economy, with sustainability conditions, element crucial for population containment and revitalization (holding young people) and the relief of local businesses at the sectors of local economy (agricultural sector, civilization, tourism).

\subsection{Visitors of the area}

offering to them a «tourist product», this is responding to new demand trends in the tourist market and emphasizes harmonization in the natural, cultural and human environment. At the same time in quality, authenticity, variety, visitor education, recreation, etc., while this transmitted image leads to the quality of life of all and to the socio-cultural of the destination. For our area of study, according to our research, the implementation of a development model based on alternative and specific forms of tourism is capable of making a decisive contribution to the upgrading of the tourism product by generating multiplier benefits for the local economy by delivering, at the same time, emphasis on maintaining the viability of the area. 


\section{References}

Appadurai, A. (1986). The Social Life of Things: Commodities in Cultural Perspective. Cambridge: Cambridge University Press

Butler B. and Rowlands M. (2012). Cultural heritage. At Gialouris, E. (ed.) material culture: Anthropology in the country. Athens: Alexandria.

Bitsani P. E. (2004). Cultural management and regional development: Ref. Athens: Duonic.

Keeeves J. (1988). Educational Research, Methodology and Measuremend and Indernational Handbook. Oxford: Pergamon Press

Nitsiakos, V. (2016). Traditional Social Structures. Ioannina: Isnafi

Pharmakis, N. (2009). Introduction to sampling. Thessaloniki: A\&P Christodoulidis. 